\title{
ORGANISATIONAL GREEN BEHAVIOURAL CHANGE: THE ROLE OF CHANGE MANAGEMENT
}

\author{
Muo Ik \\ Olabisi Onabanjo University, Ago-Iwoye, Ogun State, Nigeria. \\ Email: muo.ik@,oouagoiwoye.edu.ng; muoigbo@yahoo.com \\ Adebayo Adepoju Azeez \\ Doctoral Student (Management), Olabisi Onabanjo University, Ago-Iwoye, Nigeria. \\ Email: bayoazeez34@gmail.com
}

Received: 3 March 2020. Revision received: 3 April 2020. Accepted: 15 May 2020

\begin{abstract}
The pervasive environmental crisis across the globe has been traced to unsustainable business practices of corporations. This live-threatening phenomenon continues to generate vivacious debates, with scholars and other green stakeholders suggesting certain behavioral patterns as a solution to the scourge. However, while some organisations are realising the need for green processes and behaviors to key to sustainability practices, they are being confronted with the dilemma of the most effective ways to go about it. Organizational Green Behaviour Change (OGBC) the process actually requires complete overhauling of the entire system because it will touch all aspects of the organization and likely to alter the status quo with a possibility for change resistance. Hence, the role of Change Management is inevitable to have a seamlessly OGBC process in an organisation. Consequently, this paper attempts to review the role of Change Management in the successful delivery of OGBC vis-a-vis resistance to change (RTC). The paper adopts a content-based literature review methodology to achieve its set objectives. Findings suggest that organisation change managers need expert support toward a successful OGBC implementation to enable them to achieve desired OGBC outcomes efficiently. Secondly, it reveals that for organisations to record success in the OGBC process, all stakeholders (internal and external) interests and concerns must be taken into account ab initio. Thirdly, the paper highlights the need for a real link between Change Management and OGBC for effective management of RTC in the OGBC process. Lastly, the study admits its inability to report its findings quantitatively, and recommend active involvement of change management scholars in the growth and development of green literature for sustainability sake.
\end{abstract}

KEYWORDS: Change management, Green organizational behaviour, Resistance to change, Sustainability.

JEL CLASSIFICATION: D62, D78, D81, D83, I31, L26, L50, M10, O14, O30, Q00.

Reference: Ik, M. \& Azeez, A. A. (2020). Organisational green behavioural change: The role of Change Management. International Journal of Entrepreneurial Knowledge, 8(1), 34-48. doi: 10.37335/ijek.v8i2.98

\section{INTRODUCTION}

The need for green behaviours is increasingly on-demand in many organizations due to the rising cases of environmental challenges globally. Hottenrott, Rexhäuser, and Veugelers (2016) argue that attaining environmental sustainability demands a radical departure in employees' behaviours from the old businessas-usual ways motivated solely by profit maximisation. Getting an organization to change into green practices to foster sustainability will require a workforce to develop pro-environmental skill-sets in order to complement technology in pursuit of green objectives. Existing literature (e.g. Sußbauer \& Schäfer, 2019; Sapiro, Brun \& Fordant, 2019) documents the role of government in achieving environmental sustainability, which was primarily by legal compulsion. However, efforts to compel organizations to eschew their old unsustainable business practices attract little or no results. In fact, instead of the threat and coercion of the law to control the situation, it continued to worsen the global environmental conditions. Mostly, this phenomenon has been blamed on the weak institutions, as agents of government lack the political will to enforce environmental laws. It is thus crystal-clear that most regulatory regimes are incapable of addressing poor environmental management practices by diverse organizations. 


\section{INTERNATIONAL JOURNAL OF ENTREPRENEURIAL KNOWLEDGE}

Issue X, volume X, ISSN 2336-2960 (Online)

www.ijek.org

Despite the damage caused by poor environmental management many organizations still fail to implement OGBC. However, pro-green behavioural change in organisations is inevitable in organisations if we are to attain sustainable development. Thus, organizational members' reorientation towards environmentally friendly behaviour in all aspects of business operations is essential. Although, this cannot be achieved through the coercion but by creating an environment in which people willingly accept the need and assume responsibility for environmental sanctity. Consequently, employees' behavioural will equally require comprehensive overhauling of the organizational policies and culture. In a sense, people at all levels in the society must, first of all, recognize their primary responsibility to prevent and preserve the natural environment. Since the rescue mission of redeeming the environment from the total destruction is a collective responsibility, the underlying causes (majorly behavioural) should be addressed wholeheartedly. Hence, getting organizational members to drop their unwholesome behaviour toward the natural environment will go a long way to help to achieve sustainability.

The negative consequences of poor business-environmental behaviour, which includes, the devastation of biodiversity, ocean surge, soil eruption among others, necessitate appropriate behaviours in organizations (Hottenrott, 2016; Sawant, Mosalikanti, Jacobi, Chinthala \& Siddarth, 2013). No doubt, unsustainable business practices which some refer to "business-as-usual" is single greatest cause of current global environmental challenges and this can actually be corrected through the enthronement of new sets of behaviour in our organizations. Thus, promoting proenvironmental behaviour in organizations which the researchers refer to in this study as "Organizational Green Behavioural Change (OGBC)" is a solution to the pervasive environmental crisis. Literature shows that green behaviour in the organization has been investigated from different perspectives. For example, Khan (2015) views it from the human resource management angle and examines green policies within the framework of employees' management practices to transform an organisation into a sustainable organization. On their own, Gosling, Jia, Gong and Brown (2016) investigate the role of leadership in the acquisition and dissemination of green knowledge and strategies within the purview of the green supply chain to enable an organization to embrace sustainable development practice.

Furthermore, Loknath and Azeem (2019) from the mainstream management point of view asserts that the excruciating level of environmental degradation occasioned by industrialization as a matter of necessity demands interdisciplinary intervention towards promoting the concept of "greening". Delmas and Blass (2010) form an accounting and finance perspective advocate for transparency in the evaluation of the corporate social and environmental performance of organizations in terms of reporting metrics. What can be made of Delmas and Blass's argument is simply for organisations to be sincere in their sustainability mantra and not mere mouthing greening propaganda. However, none of the authors consider the role of change management practices in the OGBC process nor explains how to handle possible resistance to change (RTC) in the process of managing the transition from the old business as usual practices to the new pro-environmental management the organization. More so, these studies fail to examine the potency of the change management process in integrating the interest of the stakeholders in the march towards OGBC. Hence, the link between change management and organizational greening remains largely unexplored in many research works to the best of the researchers' knowledge. Thus, this paper tends to analyse the role of change management in the Organizational Green Behavioural Change (OGBC) while addressing this gap in the literature. Therefore, the main justification for the study is to expand the frontiers of knowledge by integrating behavioural sciences (change management practices) and environmental management sciences (greening) so as to improve on the current environmental challenges facing the world. It is, however, a cross-disciplinary approach to severe global challenges. And it aimed at helping business organisations and entrepreneurs to develop new skill sets required for effective change management in relation to the environment. 


\section{INTERNATIONAL JOURNAL OF ENTREPRENEURIAL KNOWLEDGE}

Issue X, volume X, ISSN 2336-2960 (Online)

www.ijek.org

\subsection{CONCEPTUAL LITERATURE REVIEW}

\subsection{Organisational Greening Behavioural Change (OGBC)}

According to Sawant et al. (2013), green management is a social corporate responsibility in support of sustainable development to curb negative business activities that adversely affect the environment, with dire consequences for humanity. The trends of globalisation, civilization, competition, demographics changes are among the factors aggravating the current environmental challenges. Since business organizations are artificial habitats of the natural environment, they ought to maintain flexible models that also change in line with unfolding changes in the environment. However, environmental forces generally are shaping the pattern and direction of organizations' decision-making process. As a result, business organizations are compelled to have a paradigm shift through the modification of goals and strategies in dealing with unfolding changes. Thus, organisations need to be adaptable and flexible in the face of ever-increasing volatility and complexity of the $21^{\text {st }}$ century (Dedahanov, Rhee \& Yoon, 2017). In another account, Muo (2014) argues that change is an inseparable and permanent feature of organisational life. Again, the role of employees in helping organizations to withstand environmental flux and maintain stability in the face of turbulence cannot be overemphasized. In other words, organisations must learn effective change management process particularly the OGBC in order to derive superior outcomes.

In addition, organisational greening behaviour should be a watchword for the management before environmental sustainability goals can be achieved. According to Scott (2010), several conceptualizations of employee contributions towards proenvironmental behaviours that may positively influence management practices can be differentiated. In the first instance, the focus is on employees as the receiver and the user of green information or knowledge to improve products and services developed according to the dictate of eco-innovations. In the second filament, therefore, the focus may be on directing the employees' knowledge and creativity towards improving work processes and routines, which are capable of impacting positively on the environment. However, this could come through a sustainability mindset such as early detection of the root cause of pollution and toxic emissions. The third strand, however, may be regarded as part of holistic green strategies for the work processes which also involve incentivizing superior contributions and innovation performance in view of keeping employees motivated to imbibe proenvironmental behaviours for as long as they stay with the organization (Gosling et al., 2016; Süßbauer and Schäfer, 2018). Given these perspectives, employees are becoming increasingly more valuable as organizational resources, owing to their capability to exhibit certain positive habits or dispositions that engender collaboration toward promoting greening during the OGBC process.

In view of the above, a configuration of holistic organizational green behavioural change strategies by organizations can help them to rise above the quick environmental fixes for mere profit maximization to developing a green culture. No organization can thrive and survive unless it is able and capable to nurture talents that are capable of creativity and innovative performance in addition to technological forces. For instance, Eze, Abdul, Nwaba and Adebayo (2018) argue that it is actually with the support of intrapreneurs that many organizations are able to transform their dreams into realities in the form of goals accomplished. Thus, organizations perceive intrapreneurs as catalysts through which organizations achieve certain goals and objectives. The essence of intrapreneurs is to complement the effort of entrepreneurs in getting things done in the most effective and efficient manner possible on the one hand. On the other hand, intrapreneurship can be a formidable tool for achieving sustainable development through business organizations. In other words, green entrepreneurship/organization needs individuals of eco-friendly (green intrapreneurs) to survive.

\subsubsection{Organisational Green Change in the Environment}

Organisational change management is a process in which a group of people within a formal boundary and common purpose agree to a series of actions aimed at taking the organization from one point to 


\section{INTERNATIONAL JOURNAL OF ENTREPRENEURIAL KNOWLEDGE}

Issue X, volume X, ISSN 2336-2960 (Online)

www.ijek.org

another within a time frame. In the case of green management change, it is to prevent certain influences from the environment or purely as a response to particular demands from the environment. This is likely to be a continuum since the organisational environment is dynamic. For an organization to manage change successfully on an ongoing basis, it has to be organized, coordinated and focused because the environment itself is dynamic. For instance, Akinyele (2011) posits that change management represents the way and manner organisations manage the change process, which starts from initiation and articulation phases through take-off, execution, evaluation and review phases. Thus, organisations being artificial and living entities are prone to constant change which appears to be serial in nature. Dhir (2019) describes the environment as Volatile, Uncertain, Complex, and Ambiguous (VUCA). In other words, the environment is in a state of flux that usually informs organizational change.

In view of the above, Banjo (2018) posits that organizations have definite goals, can only be achieved through proper coordination of efforts, resources, and strategies. Scott (2010) opines that since organizations are social structures that have attained some degree of resilience through cultural, cognitive, normative, and regulative capacities, they can provide meaning and stability to the environment through related activities and resources. Moreover, irrespective of an organizational proprietary vision and goals, it operates within an environment which directly or indirectly affects its workings in many ways. The change may be internally or externally motivated and it could either be positive (e.g. value creation through offering) or negative (e.g. environmental degradations). Of course, the change aspects may include; strategic, cultural, processes, procedures and systemic in order to either reposition to maximize opportunities or readjust to minimize threats within the environment. Albeit, organisations would appreciate any change that is internally motivated than that which externally motivated for many reasons which include but not limited to costs and reputation. Thus, organizations are able to pursue their legitimate operations in the environment by synthesizing various plans which include image-making for a positive reputation into a cohesive whole while continually accomplishing definite goals. In other words, organizations must be capable of integrating social, economic and environmental objectives by taking cognizance of sustainability.

Often times, environmental realities force organisations to change certain aspects of their operations (Muo, 2013a). Hence, organisations have limited control over the direction and magnitude of the change. Also, O'Reilly and Tushman (2004) posit that some aspects of organizations' operations may lead to discontinuous innovations or profoundly alter the basics of productions in which it affects competition as well as rendering extant work methods obsolete. Thus, organizations must possess a kind of orientation or reorientation as the case may be, needed to drive certain change successfully within the environment. However, researchers (e.g. Zelm, et al., 2015; Muo, 2014) have always been interested in understanding various signals pointing to the need for an organization to embark on the change as well as a series of workable strategies to navigate through the challenges of the change process. More so, it is also necessary to consolidate on the successes recorded or learn from the loss emanating from the change in other to overcome unnecessary vulnerability in the environmental framework.

Furthermore, the ongoing debate on whether organizations are deliberate and genuinely pursuing environmental sustainability alongside profit maximization remains popular in the contemporary world. Although many organizations are very deceptive in a clever way in making people believe that they are sincere eco-oriented organisations just to portray them in a good light when the contrary is actually the case. For instance, the United Nations Environment Programme (2015) posits that organisations make a series of decisions with many negative tendencies with dare consequences on the environment in order to make a profit. This seemingly hard to dispute argument explains the reason why organizations have come under intense pressures to adopt the "green business model". The UNEP (2015) also suggests that organizations should develop several methodologies, tools, procedures, plans, and techniques for assessing their operational environmental performance in order to show sincere commitments to environmental sustainability on the same scale with profit maximization. Thus, the concept of 


\section{INTERNATIONAL JOURNAL OF ENTREPRENEURIAL KNOWLEDGE}

Issue X, volume X, ISSN 2336-2960 (Online)

www.ijek.org

organizational green behavioural change represents an important area every organization should pursue, considering Howard and Pfeffer's (1976) argument on the intertwined nature of organizations and the environment. Hence, organizations have an obligation to ensure equal attention between profit-making and the maintenance of the natural environment because it is this the natural environment that warehouses all organizations big or small and all their possessions including human resources.

\subsubsection{Green Change Management Process}

Literally, the change process involves environmental scanning for information gathering and analysis for the purpose of making decisions. By extension, execution and evaluation of those decisions follow, in order to ensure that the objectives are being achieved and where not being achieved to determine the cause of the deviation and take appropriate corrective measures. For example, there was a kind of 'convergent change' during the early years of the modern era (post-70s) in the organisational lives in which the change processes produce relatively similar outcomes. During this period, too much emphasis was laid on 'isomorphic change' (Scott, 2010). Thus, the then change process to a large extent focuses on the internal processes and procedures to produce more coherent and homogenous structural outcomes. DiMaggio and Powell (1983) as cited in Scott (2010) describe this situation as coercive, normative, and mimetic pressures to become more responsible. Of course, organisations were somewhat reactive in their response to change rather than proactive, a method that is counterproductive to modern days environmental realities. During the $21^{\text {st }}$ century, however, organizations have a lot of environmental forces to cope with, in the course of survival, which includes operators under the umbrella names of the green movement, friends of the earth among others.

Thus, the demand for environmental accountability from business organizations keeps growing in view of ensuring sustainable development. Against this backdrop, green scholars (e.g. Loknath \& Azeem, 2019; Hassan \& Kohuy, 2016)) continue to set new research agenda toward helping business organizations and entrepreneurs to develop skill sets required for effective change management in relation to the environment. Indeed, this yearning for environmental sanity gives credence to green entrepreneurship in preference to the traditional business outfits, which are being coerced to respect the right of the environment. For instance, in most organizational change studies particularly the organizational green behavioural change, the focus is actually on the ascertainment of a pattern of behaviours an organization requires its employees adopt so as to recognize the importance of natural the environment in the scheme of things and work towards achieving environmental sustainability without losing focus in the profit maximisation aspect of the business. Khan (2015) posits that the orientation of the senior managers in a particular organisation would influence the behaviour of other organisational members in the context of environmental management. However, in the face of diverse influences and interests, management is faced with unprecedented pressures to take mutually beneficial actions in their operations. Gosling et al. (2014) posit that organisational leadership should assume the focal role of initiation, acquisition, and dissemination of sustainable practice-related information in the organisations.

\subsubsection{Resistance to Green Change}

While preparing for change, it is important that organisational management is conscious of peoples' mind-sets with respect to the change being proposed and be ready to deal with any opposing view or concerns constructively without necessarily breeding contempt. Muo (2014) posits that careful handling of organizational members' behaviour during the change process is critical to the success of the change outcome. This is to some extent true particularly with the organisational green behavioural change (OGBC) which requires employees to drop old behavioural patterns for green behaviour. Although, doing this requires organizational management to also drop the business-as-usual principle for green management principle, to be able to inculcate proenvironmental behaviour in other members of the organisation. This no doubt is a process that involves shifting from an image to the reality by creating a robust and comprehensive collaborative and communication mechanisms that guarantee effectiveness. 


\section{INTERNATIONAL JOURNAL OF ENTREPRENEURIAL KNOWLEDGE}

Issue X, volume X, ISSN 2336-2960 (Online)

www.ijek.org

More so, organizational managers are expected to be openhearted as well as exhibit the professionalism of consultants rather than the character of the bosses during the OGBC process. This is likely to motivate and encourage employees who ordinarily are uncomfortable with the proposed green change to come forward and air their opinions or concerns. Once this conducive ambiance is created and employees take advantage of it to open up, change managers also have a great opportunity to clarify some grey areas. Indeed, the fraction of employees that earlier appeared aberrant to the proposed green behavioural change programme may turn out to be a catalyst for change once they are convinced that their complaints and apprehension have been honestly received, carefully evaluated and meaningfully responded to in mutually beneficial manner. For example, Abdelnour, Hasselbladh and Kallinikos (2017) argue that people are critical to the organisation's ability to promote environmental sanctity, which is also critical to organizational survival. Thus, the organisation owes its existence to the environment being part of the products of an environment. In other words, organisations must come to the realization of the fact that both the entrepreneurs and their establishments including other stakeholders and the resource, inputs are elements of the natural environment.

In addition, all outputs of organisations end up in the market, which is located in the environment whether physical or virtual in which the outputs (goods or services) are being exchanged for value. Through this exchange process, the organisations earn profits, which they need to continuously fulfill their perpetual succession principle. Hence, it is important for organisations to heed the call for OGBC hoping it will help them to imbibe green behaviour that leads to environmental sustainability. However, resistance to change is an element of change that organisations must always take cognisance of in the course of the OGBC process. Resistance to change occurs when an individual or group of people with a common goal within a social setting resolve to behave or act in a manner variant to the acceptable mode of behaviours and ready to defend their actions through rationalisation of logic. According to Muo (2014), there are various reasons why people resist change but usually, normative reasons which may include economic, social, and emotional. Hence, it is absolutely necessary for the management or the change drivers to always consider all key factors such as organizational configurations, job groupings, reporting relationship among others as relates to the proposed change.

Also, there should be an honest review of those key factors in the light of available evidence or resources. By so doing, an organisation can envisage some challenges in the change process and be proactively buffered for those challenges, which may include resistance to change even at the early stage. Thus, people can be incontrovertibly unpredictable because they can at a different points during the OGBC act in inconsistent manners. More often than not, resistance to change is portrayed as a negative obstacle against the will of the organization that must be repelled by all means should an organization crave to move forward in its foray. Contrary to this view, if only the change managers can give those people view as though trying to resist the change an opportunity to express themselves, they can come to the realisation that their concerns can be useful rather than antagonistic and intended of complicating the change process as earlier thought. For instance, Maris (1993) posits that the process of reform is inherently conflicting because it gives people the opportunity to assimilate change and interpret it in their own understanding. In other words, the long-held assumption that resistance to change reveals the enemy of organisational progress is often misleading.

However, it is commonplace to find people trying to repel the implementation of new initiatives like OGBC simply because it is capable of altering the status quo in the organisational settings. In his own wisdom, Lewin (1947) posits that institutionalising new change programs would encounter some forms of resistance no matter the level of engagement that may have been predated the change launch. Muo (2014) indicates that building a constructive disagreement into the change process and getting employees actively involved can be an effective way of handling change management in an organisation. Thus, organisations must ensure that every stakeholder to the proposed change at different levels is duly carried along and encouraged to open-heartedly engaged in the change process. In other words, there should be 


\section{INTERNATIONAL JOURNAL OF ENTREPRENEURIAL KNOWLEDGE}

Issue X, volume X, ISSN 2336-2960 (Online)

www.ijek.org

a paradigm shift away from the old change management philosophy that is quick to take a defensive role whenever employees are expressing their uncomfortableness about the proposed change and brand them as "anti-change workers", to an open-minded management that welcomes individual differences and accommodates the concern of every individual during the change management process in the organization.

Thus, it is natural for people to stand in the way of change simply because they have learned from the experience that at the end of the day, they are not likely to remain in the same position or status from where the change met them. This is no surprise that Muo (2013a) argues that change will create a kind of variability in peoples' attitude, behaviours, habits, values, orientation, group norms, and even organisational inertia. Hence, resistance to the change can be minimized by running an open door system that encourages collaboration and participation on the basis of mutual trust, openness, and respect with commensurate group reward structure capable of promoting professionalism (Loknath \& Azeem, 2019). Therefore, since the permanent feature of the environment to which organisations are situated is "flux", constant change is inevitable to maintain their relevance. It is also necessary to keep review and renew organisational legitimacy to keep creating value in society.

\subsubsection{Dilemmas in Green Change Management}

Decisions related to organizational greening behavioural change (OGBC) come with some level of uncertainties. The future is unpredictable and as such, decisions before and during the OGBC process are mostly taken under the conditions of risks. Therefore, for an organisation to reduce the negative influence of risks due to uncertainties, emphasis should be placed on human resource development. This is so because real competencies reside in human resource, not in the technology or any other organizational material resources. Muo (2013a) argues that organizations must be sensitive to red flags as premature warning signals in the change management process. Thus, organizations can mitigate the effect of uncertainties by considering every aspect of the system and pay attention to details in the decision environment (Abdelnour et al., 2017). And, because it is very easy to deviate from OGBC action plans, outcomes are not always as expected. Hence, organizations must be able to properly harness the peoples' competencies before to ensure that change is in the desired direction and outcome.

Additionally, Muo (2013b) asserts that over-reliance on technology during the change process over and above the human resources can increase the possibility of failure in the change process. Thus, the human aspect is very germane to the successful implementation of change action plans and outcomes since the transition process from traditional organizational/entrepreneurial practices to green organizational/entrepreneurial practices requires employees to imbibe proenvironmental behaviours. In other words, because organizations exist within the general environment, it makes them vulnerable to environmental forces. However, organisations cannot sufficiently exist without an environment to which they owe their survival, despite numerous risks. Muo (2013a) argues that there is a direct relationship between risks and rewards. Traditionally, each organisation tends to decide the level of risks to take visà-vis strategies to adopt to increase profitability. Unfortunately, this is not always the case in greening management practice simply because management sees every phenomenon within the environment including the organisation as a victim of the environment. Somehow, the state of the environment also determines the state of every other thing within. Hence, selfishly deciding which of the environmental deliverables to assume and which ones to ignore in order to be efficient in organizational operations may no longer be valid in the face of pervasive environmental challenges of the $21^{\text {st }}$ century.

Furthermore, it is increasingly becoming mandatory for organisations not only to actively participate in the general environmental management but to also be proactively engaged by greening its processes. Although, the direction to which the OGBC should take for successful navigation through the traditional business model to green environmental sustainability remains entangled. The most popular way in which this type of change could occur is classified into two strands. The first strand, in this case, could be 


\section{INTERNATIONAL JOURNAL OF ENTREPRENEURIAL KNOWLEDGE}

Issue X, volume X, ISSN 2336-2960 (Online)

www.ijek.org

internally instigated (initiated/emanated from the top down or in reverse order) in which case, the organisation itself causes the change to happen like what we see in the most of green entrepreneurship firms. On the second strand, change is usually environmentally induced in which case, only the proactive organizations promptly identify and acknowledge the need for change and so launch it before it becomes an emergency. This is unlike the reactive organizations which are hell-bent on the old "business-as-usual" practice until environmental forces compel them to comply, with higher cost in reputational damage. Typically, this happens when green consumerists boycott the patronage of a particular brand due to failure to adhere to green practices. However, Schein and Almen (2019) assert that change is better to be effected through teamwork, incorporating appropriate incentive structures. Unfortunately, many organizations have individualistic customized incentive schemes, which further impoverishes teamwork and stifles the OGBC. The reason is that individualism is synonymous with internal competition which makes people fake team spirit as it is commonly seen in most of the profit-oriented organisations.

However, the dilemma before organizations particularly the already existing ones, which are used to the "business-as-usual" business model that focuses on profit maximization at the expense of sustainable development is how to get employees jointly share proenvironmental values. It is also necessary to reward teams collectively and hold them jointly accountable for environmental sustainability. Since it is clear that the world is no longer kind to management practice that treats environmental issues in business with levity, many organizations are beginning to review their business operations with a view to embracing green practices. This has not been so easy for some due to the narrow thinking of many change managers who believe that once a good enough case for OGBC is presented to the organizational members to work together, somehow, magically, teamwork will fall in place. However, this kind of assumption concerning change management can only increase the incidence of pretention and lipservices without actually leading to a collaboration for the common objectives of OGBC. This is because already, they are on an individual incentive system and are separated psychologically. Consequently, organizations must strive to synergize the system, encourage open information sharing and embrace genuine feedback by ensuring employees jointly take responsibility for the OGBC process as well as jointly holding them accountable for the outcomes.

\subsubsection{Green Change Management Strategies}

According to Aladwani (2001), implementation of improvement strategies such as OGBC mostly involves deliberate and meticulous actions. Thus, accommodating and listening to internal customers is critical to the smooth running of the OGB change process. For the change managers to navigate the complexity within the organizational settings as it relates to green change behavior, management must consider an integrated process-oriented framework that comes in phases namely; information gathering, strategy formulation, strategy implementation, and performance evaluation.

\section{Information gathering phase}

The very first step toward effective OGBC change management is to identify the attitudes of individual customers (internal and external) and other stakeholders in view of addressing questions such as (1) who are the individuals and/or groups that are likely to be affected by the proposed change? (2) what is likely to be the direction/magnitude of the effect (positive or negative)? (3) what may be their response following the effects? (4) what are their values and beliefs? (5) what are their interests among others? The ability to provide satisfactory answers to these fundamental questions would go a long way to help the organisation to have access to needed information to manage a successful OGBC process. Hence, this is a good starting point towards OGBC realization of expected or projected outcomes. Interestingly, stakeholders are always eager to cooperate with organizations when they understand that the project the organisation is about to embark on will affect them positively. Also, they are equally ready to release helpful information though that is strictly in line with their beliefs and value system to the organization especially when it can be established that what the organisation is using the solicited information has a wider benefit on the society. 


\section{INTERNATIONAL JOURNAL OF ENTREPRENEURIAL KNOWLEDGE}

Issue X, volume X, ISSN 2336-2960 (Online)

www.ijek.org

Although, this is not to say that some stakeholders will have reservations when it comes to releasing information. Thus, Harney (2016) opines that some stakeholders may raise issues concerning their negative experience with the organisation's products/services, or may not appreciate value enjoyed from using organization's offerings which may affect the accuracy of the information provided. Some of these reservations an organisation is likely to encounter from stakeholders may include the belief that a certain aspect of an organisation's operations pose threats to their wellbeing and then perceive such an organization as environmentally irresponsible. This is usually caused by the failure of an organization to work within the scope of the green process (Ivancic, Mencer, Jelenc \& Dulcic, 2017). Of course, we can have yet another group of stakeholders who may even offer themselves unsolicited for the propagating of the organisation's goodwill just because they feel that it cares for them by being environmentally friendly and sustainability resulting in positive reputational growth.

\section{Strategy formulation phase}

At this phase information gathered at the preceding phase is filtered and analyzed by subjecting it to an intense debate after which decisions about the OGBC process are made. For the benefit of the doubt, these decisions are thoroughly reappraised to ensure that nothing material is excluded and nothing irrelevant is included before disseminating to parties to OGBC process internally and externally. At this point, change managers have a responsibility to explain and clarify all the gray areas to those that are affected by those decisions. There is also a regular follow up to ensure that all ambiguities are resolved so that everybody has a full grasp of the need for the change, timeline and deliverables and ultimately expected outcomes to be achieved.

\section{Strategy implementation stage}

At this stage, the change managers move on to the OGBC process implementation. Sawant et al. (2013) posit that every organization members must be convinced at this level that the planned change is absolutely necessary and their commitment to the adoption of greening the practice is a desirable goal. If this is achieved, implementing OGBC becomes more convenient for the change participants, who are willing to collaborate and share information accordingly. According to Harney (2016), a three-level action process (think-feel-do) provides a good framework for this OGBC stage because in an attempt to change employees' attitudes towards greening, their cognitive capacities must be able to accept the change. This can be assessed by the level to which employees are open and free to one another in terms of information and communication flow. However, upon attaining success at this level, an organisation can capitalize on it by having either the marketing managers or the brand people to communicate the success achieved effectively to the potential beneficiaries of the benefits and even the market at large. Junior, Galleli, Vázques and Sảnchez-Hernảndez (2016) argue that if such information dissemination to external stakeholders are done by customizing it into the products or marketing the campaign, it would be an effective marketing tool for competitive advantage. Hence, organizational managers have a duty to create effective green awareness in their organization and be honest enough to walk their green talk through consistent communication of green benefits to employees.

Also, the OGBC strategy implementation may fail mostly due to the inability of the change managers to create open, free and fair communication channels. The benefits of the green change process to both the organization and its members as well as the modes to which the benefits are delivered to the parties can serve as a source of energy to the parties to it to remain committed throughout the cause (Abdelnour, 2017; Hassan \& Kouhy, 2016). Nonetheless, it is important to be on the lookout for possible obstacles that may appear in the form of organizational inertia. Meanwhile, the ability to conserve achieved the success of introducing green change initiatives depends on the expansion of green management base tentacles. Thus, from the beginning, management must be clear as to what the objective of the change is and should be able to explain it to the employees at all levels. For example, management should clarify the general inputs and outputs required for the change exercise, assign tasks and roles among departments 


\section{INTERNATIONAL JOURNAL OF ENTREPRENEURIAL KNOWLEDGE}

Issue X, volume X, ISSN 2336-2960 (Online)

www.ijek.org

among others. In all, it is of the utmost importance that all hiccups to the free sharing of information and support to responsible officers for the execution of green change strategies are removed completely (Dedahanov, 2017; Aladwani, 2001), so that everything ends up in tandem with projections.

In addition, Ivancic et al. (2017) posit that strategies for behavioural change involve integrated sets of programs and plans that provide direction for members of an organisation irrespective of their departmental affiliation to move towards achieving common goals. Muo (2013a) on his own opines that the most effective strategies for managing and motivating the change the process is redesigning the entire work system. Hence, getting organisations to implement the OGBC process will definitely require incentivizing green behaviour and performance, empowerment and the provision of level playing ground for every employee to contributes and participates meaningfully in the organization without fear of prejudice in whatever disguise. In other words, discover the motivation for green behaviour as well as developing effective strategies for OGBC towards getting employees imbibing green behaviour differentiates sustainability-oriented organisations.

\subsection{THEORETICAL REVIEW}

Several theories attribute individuals' willingness to do things differently, such as an attitudinal and behavioural change to the intrapreneurship characteristics in an organisational set-up (Eze et al., 2018). Although motivation has a way of directing one's behaviour towards particular goal attainment, it begins from a felt need to perform certain behaviours to enhance productivity or effectiveness. In this context, three interrelated factors namely; needs, drives, and incentives are critical to goal attainment. Management, therefore, needs to acknowledge this and pay due attention to their application to really bring about true motivation. Muo (2014) argues that when needs are felt, drives energize individuals towards achieving the goals while in satisfying those felt needs equilibrium point is being restored. In other words, motivation can be regarded as a software to which behind the inner force that energizes the hard-drives which is represented as the degree of efforts and determination placed on the attainment of the goals.

Thus, many conceptual perspectives have been deployed in view of explaining how people really get motivated. On a general note, these perspectives can be streamlined to instinct and extrinsic approaches in which, the latter believe that people are primarily inbuilt with certain instincts that make them behave in certain ways depending on the direction of the feelings regarding the need to be met. The extrinsic approaches on the other extreme hold the view that people are driving by the desire to achieve some values or goals that are outside of their immediate (inner) reach. In this case, motivation is a function of an individual's thought pattern, orientation, expectations and need goals which can either be intrinsic or extrinsic. Hence, there are many theories of motivation but the researchers chose to review the two considered most relevant to the present study.

\subsection{Equity Theory}

Equity Theory as propounded by Adams (1961) has its argument built on the three major building blocks. These building blocks include inputs, outcomes, and reference person however, the major thrust of these constructs argue that inequity exists whenever an individual's input and output ratios show a wide discrepancy from that of a reference source, inequity exists while the reverse is the case whenever input and output ratios show close or equal. Therefore, inequity whether positive or negative represents a dissatisfaction and usually, it prevails in the form of conflict/anger (under-paid) or self-pity/guilt (overpaid). Hence, the motivation is for managers to ensure employees are closer to the expected goals at all times.

\subsection{Goal-Setting Theory}




\section{INTERNATIONAL JOURNAL OF ENTREPRENEURIAL KNOWLEDGE}

Issue X, volume X, ISSN 2336-2960 (Online)

www.ijek.org

The goal-setting theory was propounded by Locke in 1966. According to Locke (1966), goal-setting and other work-related factors such as supervision, engagement, and involvement in the decision-making process, conflict resolution procedures, teamwork, and fairness of the performance appraisal process affects employees' performance. The goal-setting theory focuses on how the process of setting goals with the assumption that the process of goal the setting is positively related to performance. Specifically, the theory is concern about adherence to critical aspects of goal setting such as goal specificity, measurable, achievable, realistic and time-bound (SMART). However, taking cognizance of difficulties and feedback in the process has a lot to do with actual performance improvement. Thus, since, OGBC process requires cognitive modification of employees at all level, such factors as resistance to change, willingness to cooperate for information sharing, reward or incentivize superior contributions in order to reinstate desired behaviours among others have a place in goal-setting theory which could be used in the study of green change practice.

In addition, to achieve success in sustainability-oriented management practice as dictated by green management philosophy, goal content, and intensity, degree of influence, adequate energy and a high level of commitment must be invested in the change process. Thus, getting organizational members to support the green change from the old unsustainable business practices (business-as-usual) from the perspective of change management, requires that management must pay attention to the motivating factors. Thus, if employees' needs and concerns are embedded in the process of goal-setting at the outset, the achievement of the goals can be made easy. People would be clear about what required of them in the process of goal attainment as well as rewards due to them once goals are achieved. This theory in the light of OGBC toward transition or emancipation into sustainability practice, employees can make their organizations green profile rise by imbibing green behaviour knowing the reward awaits for doing so. Hence, this study is underpinned on the platform of Goal-setting theory because researchers believe that it is adequate to explain the objective of the study.

\subsection{AIM AND METHODOLOGICAL BASES}

The aim of this study is to review the role of change management in the light of the green field of study. The study further aims at analyse the link between the change management and OGBC process. More specifically, the study highlights systematic ways of inculcating green behaviours in employees as well as points to possible change resistance that an organisation can encounter in the process. Lastly, the study proffers a number of ways to deal with change resistance for effective OGBC in the organization. To achieve these objectives, the study adopts a synthesised literature review methodology. Thus, researchers have the opportunity to review a number of journal articles via the internet and manual library in order to appreciate and connect change management and corporate greening in an interdisciplinary manner, to point the way forward in the pursuit of sustainable development.

\subsection{RESULTS}

During the process of addressing the gap in the literature which borders around scanty of studies that explore the link between change management and organisational greening, we discover the importance of change management experts in managing OGBC. Although, change management is an aspect of management almost as organisation greening is also an aspect of management, it is just that organizational greening is more pervasive and transcends management field of study. The reason for this pervasiveness of greening is because it revolves around environmental sustainability or sustainable development in generic terms. Thus, we note that greening is a modern management practice that requires reorientation for the change in behaviour from old attitude to the environment. By extension, we observe that for an organisation to succeed in getting its members behaving in a green manner and embrace the green practice requires such as industry life cycle, entrepreneurship knowledge stock, knowledge spill-over, institutional frameworks, entrepreneurship financing, green entrepreneurship decision-making processes 


\section{INTERNATIONAL JOURNAL OF ENTREPRENEURIAL KNOWLEDGE}

Issue X, volume X, ISSN 2336-2960 (Online)

www.ijek.org

are all open for further clarifications. More so, we identify that the old established firms need holistic change packages. This change package of course, will involve the integration of varied interests of stakeholders into a cohesive whole through a systematic gathering and creative dissemination of those information for the purpose of OGBC to ensure desired green outcomes.

In addition, we discover that employees are usually ready to resist behavioural change process for green practice simply because they hold some level of apprehension. We then observe that this resistance to change (RTC) is more prevalent in already established organizations that have ingrained the old business management practice, which sees profit maximization as the ultimate. The reason is that the people working for these old organizations are already familiar with certain behaviours that do not recognize the environment as an important element of the business hence, they dread the change to greening. Paradoxically, the emerging organisations inherently recognise the need for environmental management in business hence, they are coming up in the form of green entrepreneurship. This category of organisations do not face as much change resistance as the older ones. Be that as it may, this study identifies a number of strategies to handle resistance to change in OGBC includes collaboration, joint reward to encourage team spirit, openness to learning and mutual respect. We also identify increased awareness of the benefits of the green practice amongst internal and external stakeholders, which leads to rising commitment, as a supportive factor. However, we observe the dilemma of many organisations in managing the transition from the old business-as-usual model to full-blown greening practice. Lastly, we recognize the ability to change management to help the organisations to have a successful OGBC management process leading to sustainable development in our society.

\subsection{DISCUSSION}

Green research is growing due to the generic issue of sustainability which is being threatened by unsustainable business practices of many organizations. Thank many scholars who are increasingly picking interest in environmental sustainability-related topics hence, many organizations are beginning to accept the need to green their business processes toward achieving sustainability. While prospective organizations are also developing in the form of green entrepreneurship. This is not to say that government at all level do not do their bits in terms of enactment of laws and establishment of regulators to enforce those laws but the reality is the legal regime remains largely ineffective due to many reasons which include lack of political will to enforce the law and weak institutions. Away from the legal regime, it is now clear to us that we do not need really need the government to run after us before taking responsibility for environmental sanctity because we are all victims of the environment. In other words, the better or healthier the environment, the better and healthier everything within the organization is and the reverse is the case for degradation and bastardization of the environment. Thus, organizations need not wait for any government agency to coerce them before rising to the occasion of proactive environmental management.

If not for any reason, organizations should also pay equal attention to the management of the environment as in the case for profit maximization but because they hold their wellness and survival to the natural environment. Take for instance, air, water, land, raw material, human material and financial resources that serve as input for organizations are all products of the environment on the one hand. In another hand, after the transformation process organizations perform on those resources, certain outputs are derived in forms of products or services which cannot be converted to money value that organizations actually need to service perpetual succession principle until those outputs are exported back into the environment. So, how sensible it is for any organization to hell-bent on profit maximization at the expense of environmental sustainability? Research also shows that earth integrity is also vulnerable to damage due to the disastrous practice of many organizations meanwhile, we only have one world to ourselves which if allows to destroy everyone and everything is also destroyed. In other to promote proenvironmental behaviour in organizations, we propose behavioural change for greening practice 


\section{INTERNATIONAL JOURNAL OF ENTREPRENEURIAL KNOWLEDGE}

Issue X, volume X, ISSN 2336-2960 (Online)

www.ijek.org

which we enable an individual in the business world to take responsibility for environment wellbeing. For this to be possible, we suggest organisation institutionalize team rewards model which does not only foster collaboration and green information sharing but would also help organizations reduce the incidence of internal competition hence increases synergy.

Furthermore, we argue that successful OGBC strategies implementation deserve sourcing for relevant information within and outside the realm of an organization. That is, concern or complaint of every stakeholder (internal and external) must be collected and review in view of using same for the formulation of appropriate OGBC strategies to be implemented toward achieving desired change outcome without losing focus on the evaluation of those strategies vis-à-vis goals of each stage in the change process. For the avoidance of doubt, we identify people's innate quest to maintain the status quo. People are predominantly comfortable with the known zone where their status seems unthreatened despite that it is undisputedly known to everyone that for growth (individual or organization) to occur, change must take place. Yet, people resist change in various form and that is what we are seeing in many organizations which refused to green their processes despite the force of environmental factors which is more prevalent in contemporary time. Although there are many reasons people tend to reject or resist change but the majorly, those reasons can be studied under three headings namely; psychological, economic, and sociological reasons. Thus, these reasons are altruistic to the individual as an inherent part of human nature to challenge or resist anything perceived to be a threat. However, the OGBC is a changing phenomenon that requires a purge out of eco-unfriendly behaviour and internalises new proenvironmental behaviour (greening) at the workplace. Such behaviour definitely provides a mutual benefit to everyone within the sphere of the environment. Hence, we suggest ways of handling challenges of resistance to change from the sources (habits and perceived risks) in this context and demonstrate methods of integrating information-gathering phase, strategy formulation phase, strategy implementation phase and evaluation phase into a cohesive whole for the benefit of sustainability.

\subsection{CONCLUSIONS}

The paper suggests among other things that, achieving desired outcomes in the OGBC process requires adequate information, knowledge, and expertise. The positive role of change management in driving successful and efficient OGBC is identified. The study also recognise the need to integrate stakeholders' interests and concerns into the change management process to overcome friction or resistance to change. We argue that if all that needs to be known about employees and other stakeholders are known from the beginning, change managers would be better equipped and guided appropriately, thus, making green change implementation efficient and effective. At the same time, we highlight difficulties involve in OGBC management particularly the ones associated with peoples' behaviour. Also, we review resistance to change and highlight the method of handling it without necessarily having a major impact on the OGBC outcome. Specifically, we advocate for radical change in behaviour in already established organizations to enable them to imbibe green behaviour as well as canvassing for more creation of green entrepreneurship.

Therefore, we recommend that future research should focus on the nexus between the change management and performance in the organization with green practice in order to bridge the the existing gap between the theory and practice and broaden the chances of achieving environmental sustainability. We also recommend that prospective researchers should investigate what motivates green entrepreneurs to come into being and old already established organizations to migrate into greening in the future. Finally, we acknowledge the limitation to the study as researchers' inability to go to the field for data collection and failure to derive our findings from statistical analyses or empirically.

\section{REFERENCES}




\section{INTERNATIONAL JOURNAL OF ENTREPRENEURIAL KNOWLEDGE}

Issue X, volume X, ISSN 2336-2960 (Online)

www.ijek.org

Abdelnour, S., Hasselbladh, H \& Kallinikos, J. (2017). Agency and institutions in organization studies. Journal of Organization Studies, 38(12). 1775-1792.

Aladwani, A., M. (2001). Change management strategies for successful ERP implementation. Business Process Management Journal, 7(3), 1-10.

Akinyele, S., T. (2011). Strategic Marketing Strategies on the Performance of Firms in Nigerian Oil and Gas Industry. Journal of Emerging Trends in Economics and Management Sciences, 1(1), 23-36.

Banjo, H., A. (2018). Organizational structure and business etbics. An unpublished doctoral thesis (section one). Department of Business Administration, Olabisi Onabanjo University, Ago-Iwoye, Ogun State, Nigeria, 2-23.

Dedahanov, A., T., Rhee, C. \& Yoon, J. (2017). Organisational structure and innovation performance is employee innovative behavior a missing link? Career Development International, 22(4), 334-350.

Delmas, M., \& Blass, V., D. (2010). Measuring corporate environmental performance: the trade-offs of sustainability ratings. Business Strategy and the Environment Business, 19(1), 245-260.

Dhir, S. (2019). The changing nature of work, leadership, and organizational culture in future ready organizations. Claremont Colleges Theses, 1-65. Retrieved on 6/12/2019 via: https://scholarship.claremont.edu/cmc_theses/206

Eze, B., U., Abdul, A., Nwaba, E., K., \& Adebayo, A., A. (2018). Organizational culture and intrapreneurship growth in Nigeria: Evidence from selected manufacturing firms. Emerging Market Journal, 8(1), 39-44.

Gosling, J., Jia, F., Gong, Y., \& Brown, S. (2016). The role of supply chain leadership in the learning of sustainable practice: toward an integrated framework. Journal of Cleaner Production, 137(1), 14581469.

Hassan, A. \& Kouhy, R. (2016). From environmentalism to corporate environmental accountability in the Nigerian Petroleum Industry: Do green stakeholders matter? International Journal of Energy Sector Management, 9(2), 227-250

Harney, B. (2016). Strategic choice in Johnstone, S. and Wilkinson, A. (2016). An Encyclopedia of human resource management, Cheltenham: Edward Elgar, 414-415.

Hottenrott, H., Rexhäuser, S. \& Veugelers, R. (2016). Organisational change and the productivity effects of green technology adoption. Dice Discussion Paper, 206(1), 3-41.

Howard, E., A. \& Pfeffer, J. (1976). Environment of organization. Annual Review of Sociology, 291), 79-105.

Ivancic, V., Mencer, I., Jelenc, L., Dulcic, Z. (2017). Strategy implementation - external environment alignement. Journal of contemporary Management Issues, 22(2), 51-67.

Junior, F., H., Galleli, B., Gallardo-Vȧzquez, D. \& Sȧnchez-Hernȧndez, M., I. (2016). Strategic aspects in sustainability reporting in oil \& gas industry: The comparative case-study of Brazilian Petrobras and Spanish Repsol. Ecological Indicator, 203-214.

Khan, M. (2015). Green human resource management - A prerequisite for sustainable environment. Progressive in Science and Engineering Research Journal, 18(3), 24-30.

Lewin, K. (1947). Frontiers in group dynamics-concept, method, and reality in social science: Social equilibria and social change. Human Relations, 1(1), 5-41.

Loknath, Y. \& Azeem, B., A. (2019). Green management - Concept and strategies. National Conference on Marketing and Sustainable Development, 1-16.

Muo, Ik. (2013a). Identifying and minimizing risks in the change management process: The case of Nigerian banking industry. Business Management and Economics, 1 (6), 148-162.

Muo, Ik. (2014). The other side of change resistance. International Review of Management and Business Research, 3(1), 96-112.

Muo, Ik. (2013b). Motivating and managing knowledge workers: Evidences from diverse industries and cultures. Journal of Management and Sustainability, 3(2), 1-13.

Sapiro, G., Brun, E. \& Fordant, C. (2019). The rise of the social sciences and humanities in France: institutionalisation, professionalisation, and autonomisation. Journal of Social Science and Humanities, 7(2), 25-68. 


\section{INTERNATIONAL JOURNAL OF ENTREPRENEURIAL KNOWLEDGE}

Issue X, volume X, ISSN 2336-2960 (Online)

www.ijek.org

Sawant1, S., U., Mosalikanti, R., Jacobi, R., Chinthala, S., P. \& Siddarth, B. (2013). Strategy for Implementation of Green Management System to Achieve Sustainable Improvement for Eco friendly Environment, Globally. International Journal of Innovative Research in Science, Engineering and Technology, 2(10), 1-7.

Schein, E., \& Ameln, F. (2019). Relationships as a key to change. Ed Schein on the legacy and future of change management. Organizational Culture and Leadership Institute, 50(1), 141-144.

Scott, W., R. (2010). Reflections: The past and future of research on institutions and institutional change. Journal of Change Management, 10(1), 5-21.

Sußbauer, E., \& Schäfer, M. (2019). Corporate strategies for greening the workplace: findings from sustainability-oriented companies in Germany. Journal of Cleaner Production, 226, 564-577.

UNEP (2015). Guidance on Organizational Life Cycle Assessment. Retrieved on 25/11/2019 via: https://www.lifecycleinitiative.org/wp-content/uploads/2015/04/o-lca 24.4.15-web.pdf

Zelm, R., F., Muchanda, P., A., N., Velde, M., V., D., Kindermann, G., Obersteiner, M. \& Huijbregts, M., A., J. (2015). Impacts of biogenic CO2 emissions on human health and terrestrial ecosystems: the case of increased wood extraction for bioenergy production on a global scale. Journal of global Change Biology, 7(1), 608-617.

\section{BRIEF DESCRIPTION OF AUTHOR/AUTHORS:}

\section{Ik Muo, PhD}

Holds a B.Sc in Economics from the University of Ibadan, an MBA from Ahmadu Bello University, Zaria, M.Sc in Organisational Behaviour and $\mathrm{PhD}$ in Business Administration (with specialisation in Organisational Behaviour/Change Management) both from the University of Lagos, Nigeria, He is a Senior Lecturer in the Department of Business Administration, Olabisi Onabanjo University, where he is also the Coordinator of Post Graduate Programmes. He has 12 textbooks to his credit and has been a columnist with Business Day, Nigeria, since 2001. His research interest is in Organisational Behaviour and Entrepreneurship. Website: https://muoigbo.blogspot.com/ Email: muo.ik@,oouagoiwoye.edu.ng; muoigbo@yahoo.com

\section{Adebayo Adepoju Azeez}

Holds a B.Sc in Business Administration from Lagos State University, MBA from Ladoke Akintola University of Technology, Ogbomoso, M.Sc (Management), Diploma and Advanced Diploma in Human Resource Management all from the University of Lagos. He is currently a Doctoral student in the Department of Business Administration, Olabisi Onabanjo University. He is a seasoned Oil and Gas professional of close to three decades hands-on experience in the Nigeria downstream sector. His research interests include Sustainability, Entrepreneurship, Human Resource Management, and Organisational Change Management. Email: bayoazeez34@gmail.com. ORCID ID: https://orcid.org/0000-0001-6973-80442 